\title{
Linear Modeling of Marine Vessels Fuel Consumption for Ration of Subsidized Fuel
}

\section{Alireza Soleymani ${ }^{1}$, Seyed Mohammad Hossein Sharifi ${ }^{2 *}$, Pedram Edalat ${ }^{3}$, Seyed Mohammad Mahdi Sharifi ${ }^{4}$, Samad Karim Zadeh ${ }^{5}$}

${ }^{1}$ Marine Engineering Department, Petroleum University of Technology; a.soleymani@put.ac.ir

${ }^{2}$ Mechanical Engineering Department, Petroleum University of Technology, Sharifi@ put.ac.ir

${ }^{3}$ Marine Engineering Department, Petroleum University of Technology,Edalat@put.ac.ir

${ }^{4}$ Islamic Republic of Iran Railways Company, Tehran; sharifi.smm@gmail.com

${ }^{5}$ National Iranian Oil Products Distribution Company, Tehran; karimzadeh_1987@Yahoo.com

\section{ARTICLE INFO}

Article History:

Received: 7 Feb. 2018

Accepted: 19 Jun. 2018

Keywords:

Marine vessels

Fuel consumption

Linear Modeling

Regression analysis

Cross sectional data

\begin{abstract}
An approach to deal with the phenomenon of maritime fuel smuggling is to control the quantity of fuel that is supplied to vessels. For the same reason, fuel is delivered to marine vessels in Iran in accordance with the ration defined by the National Iranian Oil Products Distribution Company (NIOPDC). The ration is determined by a fuel consumption formula defined by the Food and Agriculture Organization of the United Nations (FAO) which is used to estimate the fuel cost of agricultural and road construction equipment and machinery. The use of this formula for maritime usage renders fuel allocation to vessels inappropriate. This paper makes a database containing the specifications of 452 vessels, including length, width, summer draft, economical speed, engine power and hourly fuel consumption values. Then, a linear model is estimated over the available database. Ordinary least square method is used for regression analysis. Then, the estimated linear model is compared with FAO formula and linear model is selected as the optimum model to estimate vessel fuel consumption as close to the actual value of fuel consumption as possible. This linear model contains three parameters: engines power, economical speed, and immersed volume as defined by multiplying three parameters of length, width, and summer draft. In general, the amount of fuel consumption estimated by FAO formula is about $50 \%$ greater than that estimated by the linear model.
\end{abstract}

\section{Introduction}

Fuel supply to vessels is controlled in attempts to deal with the phenomenon of fuel smuggling in the maritime domain. Therefore, fuel is delivered to marine vessels in Iran according to ration defined by National Iranian Oil Products Distribution Company (NIOPDC). Currently, this ration is based on fuel consumption formula that had been defined by the Food and Agriculture Organization of the United Nations (FAO), which is used to estimate fuel cost for agricultural and road construction equipment and machinery. The application of this formula for maritime usage has rendered fuel allocation to vessels inappropriate. So, the present study reviews fuel consumption and its effective factors for the most widely used classes of marine vessels and devises an appropriate formula for calculating fuel consumption by developing an econometric model. It is essential to define a new fuel consumption formula based on vessel specifications and its sailing details. This will help stop fuel smuggling by optimal fuel allocation, prevent financial losses to vessels owners due to overestimation/underestimation of fuel consumption which causes the vessels to carry excessive/deficient fuel for a specified voyage.

This section reviews four relevant papers that calculate ship fuel consumption by regression analysis. Hutchinson [1] investigates three types of ships including bulk, Ro-Ro, and container and presents two model types for sailing and berthing operations of each ship type as a function of ship deadweight.

Schrady et al. [2] investigate 22 classes of U.S navy ships and describe an exponential model as a function of ship speed for each class separately. 
Davie et al. [3] focus on the half of the Irish fishing vessels. They are led to a generalized additive model as a function of vessel length, engine power, fuel price, and gear type.

Hulskotte et al. [4] address nine classes of ships at berth and present nine linear models as a function of ship gross tonnage.

But, the present research considers all commonly used marine vessels and does not confine itself to some specific classes; that is, a unit fuel consumption model is defined by ordinary least square method for sailing operation of all ships as a function of more parameters, including ship length, width, draft, economical speed, and main and auxiliary engines power.

A review of literature shows that a plethora of very diverse factors are considered to affect fuel consumption: speed [2,5-8], engine RPM [9], engine power $[3,7,10]$, age [11], weather and environmental conditions (air temperature, seawater temperature, wind) [6,7,11-13], operating scenarios [11], draft $[5,7,13]$, trim [5,7], length [3], gear configuration [3], fuel price and quality $[3,12]$, fractional engine load [14], gross tonnage [4,9], deterioration of the hull, engine, and propeller [7,12,13], deadweight [1], and displacement $[6,13]$.

Data availability is the main factor limiting the selection of effective parameters. Also, NIOPDC is looking for a simple and acceptable formula to make an appropriate estimation of fuel consumption ration for all marine vessels from small-sized to large-sized. Therefore, parameters that are applicable for all ranges of vessel size should be chosen.

Finally, econometric and regression analysis is applied a restriction for variable selection. As a general rule, none of the parameters should have a linear relationship to one another [15].

This paper includes four important parameters in regression analysis, including speed, power, draft, and length. Also, according to the expert's advice, vessel width is considered as another effective factor in addition to the parameters. So, these five parameters are chosen as factors influencing fuel consumption in an attempt to model with regression analysis.

\section{Methodology}

First, the fuel consumption formula of FAO is defined and compared with NIOPDC fuel consumption method.

According to FAO's fuel consumption calculation method, the following formula can be used to estimate liters of fuel used per machine hour:

$L M P H=\frac{K \times G H P \times L F}{K P L}$

where $L M P H$ is the liters used per machine hour, $K$ is $\mathrm{kg}$ fuel used per brake hp/hour, GHP is the gross engine horsepower at governed engine rpm, $L F$ is the load factor in percent, and $K P L$ is the weight of fuel in $\mathrm{kg} / \mathrm{L}$. Typical values are given in Table 1 . The load factor is the ratio of the used average horsepower to gross horsepower available at the flywheel [16].

Table 1. The specifications of FAO's variables [16]

\begin{tabular}{ccccccc}
\hline \multirow{2}{*}{ Engine } & Weight & \multirow{2}{*}{$\begin{array}{c}\text { Fuel } \\
\text { Consumption }\end{array}$} & \multicolumn{2}{c}{ Load Factor (LF) } \\
\cline { 4 - 6 } & $\mathbf{k g} / \mathbf{L}$ & $\begin{array}{c}\text { Cons) kg/brake } \\
\text { hp-hour }\end{array}$ & Low & Med & High \\
\hline Gasoline & 0.72 & 0.21 & 0.38 & 0.54 & 0.70 \\
\hline Diesel & 0.84 & 0.17 & 0.38 & 0.54 & 0.70 \\
\hline
\end{tabular}

NIOPDC released the latest instruction on the procedure to sell fuel to marine vessels in 2016. In this instruction, fuel consumption formula is defined as below, which is basically similar to FAO's formula with some adjustments:

$F C=\frac{0.75 \times \text { Power } \times S \times \text { Time } \times 0.001}{\text { Density }}$

in which Power is total power of main engines plus half of auxiliary engines power, $S$ is $\mathrm{kg}$ fuel used per brake $\mathrm{hp} /$ hour ( $\mathrm{S}=170$ for fishing vessels and $\mathrm{S}=200$ for others), and Time is the distance (mile) per speed [17].

So, to accomplish to research target, we identified the most popular types of marine vessels in Iranian shipping companies, fuel consumer machinery in marine vessels, and effective parameters in fuel consumption of marine vessels. Also, fuel consumption data of marine vessels were gathered to establish the database. The final model of fuel consumption is formed by regression analysis.

\subsection{The Most Popular Types of Marine Vessels in Iran}

Table 2 presents the information of the registered vessels sorted by vessel type.

\begin{tabular}{|c|c|c|}
\hline \multicolumn{3}{|c|}{ Table 2. The types of Marine Vessels in Iran [1 } \\
\hline & Vessel type & 2013 \\
\hline 1 & Cargo & 284 \\
\hline 2 & Tanker & 19 \\
\hline 3 & Landing craft & 101 \\
\hline 4 & Fishing vessels & 173 \\
\hline 5 & Dredger & 22 \\
\hline 6 & Engine barge & 132 \\
\hline 7 & Passenger & 98 \\
\hline 8 & Tugboat & 410 \\
\hline 9 & Barge & 352 \\
\hline 10 & Marine bus & 141 \\
\hline 11 & Cargo boat & 4615 \\
\hline 12 & Fishing boat & 5498 \\
\hline 13 & Multi cat & 5 \\
\hline 14 & Boat & 17700 \\
\hline 15 & Special vessels & 31 \\
\hline 16 & Supply vessels & 151 \\
\hline 17 & Total & 29732 \\
\hline
\end{tabular}


According to The Ports and Maritime Organization of Iran, boats form the greatest number of vessels followed by tugboats, barges, and cargo ships [18].

\subsection{Fuel Consumer Machineries}

Main engines account for the main portion of fuel consumption by about 90 percent. So, auxiliary engines, which are responsible for power supply, and boilers, which supply steam, consume the remaining 10 percent of fuel. Boilers have been neglected due to inaccessibility to boiler specifications data and theirs running hours, low percentage of boilers fuel consumption, and the use of the recovered engine exhaust heat instead of boilers during sailing. Also, incinerators that consume a little fuel are neglected in the analysis [19-22].

\subsection{Effective Parameters in Fuel Consumption}

Five parameters, i.e. speed, power, draft, length, and width, are included in the final model. Also, for the sake of final model simplification, the immersed volume is defined by multiplying three parameters of length, width and summer draft.

\section{Speed}

According to Schrady [2], the power required to move a displacement hull through the water at velocity $\mathrm{V}$ is proportional to $\mathrm{V}^{3}$.

Górski [5] shows that vessel speed is the parameter mostly influencing the level of fuel consumption as follows:

$\mathrm{ZP}_{\mathrm{C}}=\frac{\Delta^{2 / 3} \cdot \mathrm{V}^{3}}{\mathrm{ZP}}$

where:

$\mathrm{ZP}_{\mathrm{C}}=$ fuel coefficient, $\Delta=$ ship displacement, $\mathrm{V}=$ ship speed, $\mathrm{ZP}=$ main engine fuel consumption.

Meng [6] shows that the sailing speed is the main determinant of the fuel consumption rate of a ship. An increase in the speed of a couple of knots during sailing might cause a considerable increase in bunker consumption. The so-called cubic law, namely, that the bunker consumption of a ship in one time unit is proportional to the sailing speed to the power of three, is widely adopted in maritime studies.

\section{Power}

Borkowski [10] argues that ship fuel oil consumption is proportional to ship engine power.

According to Davie [3], fuel consumption of a fishing vessel varies depending on a variety of factors and conditions, and engine power is one of the factors underpinning ship fuel consumption.

Figure 1 depicts the variation of power versus the dependent variable (i.e. fuel consumption flow rate) based on the database which will be discussed in next part, to give an overview of the existence or absence of manifest relationship. It is evident that there is a relationship between power and fuel consumption.

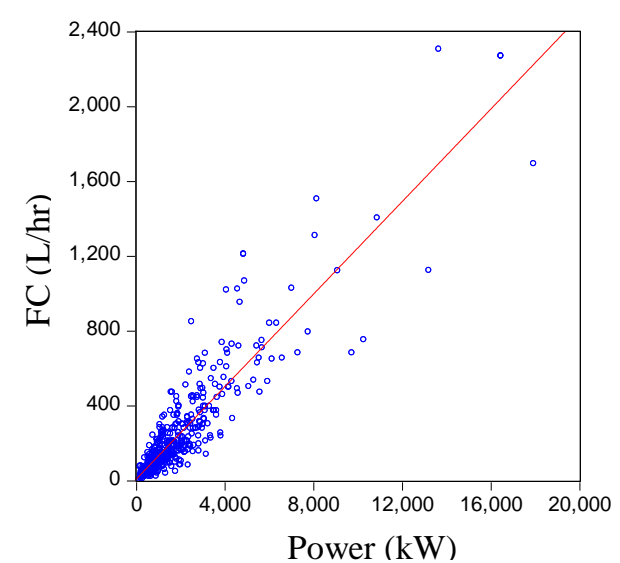

Figure 1. Variations of fuel consumption versus the independent variable (Power)

\section{Immersed Volume}

The immersed volume of a ship is estimated by multiplying three parameters including length, width, and summer draft. This volume is proportional to ship displacement. Bialystocki [13] shows that resistance and fuel consumption are increased with any changes in displacement. Meng [6] states that ship displacement is affected the resistance against its movement and, in turn, by its fuel consumption.

\subsection{Data Gathering}

Data of fuel consumption flow rate for 452 marine vessels were collected along with the details of the vessels, including length, width, draft, economical speed, main engine power, and auxiliary engines power, from the database of Maritime Sales Inc., Florida, the US.

These vessels are in various sizes and types and under convention and non-convention classes. The smallest vessel has a capacity of 7 tons and largest has a capacity of 18,012 tons. However, the gross tonnage was unavailable for 61 vessels. In terms of vessel size, the smallest is 7 meters long and the largest is 200 meters long. Also, total main and auxiliary engines power are in range of $127 \mathrm{~kW}$ to $17,925 \mathrm{~kW}$. Economical speed in data collection is an optimal speed at which a vessel usually sails.

Fuel consumption is expressed in metric tons per hour. These values are converted to liter per hour by different fuel densities $\left(\mathrm{HFO}=930 \mathrm{~kg} / \mathrm{m}^{3}-\mathrm{FO}=\right.$ $\left.890.13 \mathrm{~kg} / \mathrm{m}^{3}-\mathrm{DFO}=885 \mathrm{~kg} / \mathrm{m}^{3}-\mathrm{GO}=890 \mathrm{~kg} / \mathrm{m}^{3}\right)$. Thus, the final model will represent the amount of consumed fuel in one hour.

Data collection includes various types of vessels with different applications and capacities. This makes it possible to generate the results for the whole marine vessels with an acceptable estimation. Of course, as shown in Table 3, most vessels have a capacity below 3,000 tons; thus, the final model is more valid for these vessels than the others. Also, a major problem of 
NIOPDC in subsidized fuel allocation is related to these $<3000$-ton vessels. Our outcomes are perfectly suitable for NIOPDC to allocate subsidized fuel to small vessels.

Table 3. The classification of the vessels

\begin{tabular}{|c|c|c|c|c|c|c|c|c|c|}
\hline GRT & $Z$ & 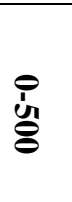 & 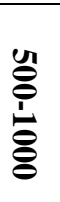 & 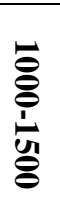 & 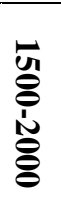 & 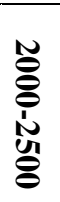 & 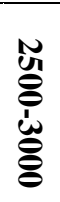 & 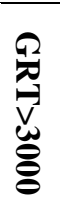 & $\stackrel{\overrightarrow{0}}{\stackrel{0}{0}}$ \\
\hline $\begin{array}{l}\text { Landing } \\
\text { craft }\end{array}$ & 1 & 14 & 1 & 1 & - & 1 & - & - & 18 \\
\hline $\begin{array}{c}\text { Supply } \\
\text { vessel }\end{array}$ & 5 & 21 & 20 & 6 & - & - & - & - & 52 \\
\hline $\begin{array}{l}\text { Passenger } \\
\text { ferry }\end{array}$ & 15 & 47 & 4 & - & - & - & - & 1 & 67 \\
\hline Cargo & 3 & 20 & 13 & 13 & 18 & 12 & 7 & 14 & 100 \\
\hline Container & - & - & 2 & - & 3 & - & - & 5 & 10 \\
\hline Tanker & 1 & 5 & 4 & 3 & 6 & 1 & 2 & 4 & 26 \\
\hline Ro-Ro & 3 & 5 & 1 & - & 1 & - & - & 8 & 18 \\
\hline Refrigerated & 1 & 1 & 1 & 2 & - & 1 & - & 1 & 7 \\
\hline Tugboat & 15 & 60 & 4 & - & - & - & - & - & 79 \\
\hline Boat & 5 & 8 & - & - & - & - & - & - & 13 \\
\hline $\begin{array}{l}\text { Fishing } \\
\text { vessel }\end{array}$ & 9 & 22 & 5 & 1 & 1 & - & 1 & 1 & 40 \\
\hline Other & 3 & 10 & 2 & 2 & 3 & 2 & - & - & 22 \\
\hline Total & 61 & 213 & 57 & 28 & 32 & 17 & 10 & 34 & 452 \\
\hline
\end{tabular}

\section{Modeling}

The collected data are of cross-sectional type, including 452 vessels or sections. Ordinary least squares method (OLS) is used for regression analysis. OLS is one of most famous and powerful methods of regression analysis. The famous German mathematician, Carl Friedrich Gauss, developed this method. So, the linear model is estimated on available database.

Finally, the appropriate vessel fuel consumption model is selected by comparing the obtained linear model with the FAO formula.

To begin the analysis, the collected data is fed into statistical software (EViews). Power is defined as the sum of main and auxiliary engines power.

The dependent variable is defined as the flow rate of consumed fuel for sailing in one hour (FC) expressed in liter per hour. Also, the independent variables are defined as immersed volume (defined by multiplying of length, width, and summer draft) in cubic meters (Volume), total main and auxiliary engines power in kilowatts (Power) and economical speed in knots (Speed).

Generally, it is reasonably expected to have positive impacts on fuel consumption by all independent variables. This has been studied in the literature review.

This section estimates the linear model. First, the colinearity of variables is tested with a visual survey. Then, the model is estimated with ordinary least squares method. This is followed by checking the statistical significance and mathematical sign of the coefficients. Also, the model validation and fitness of model are examined against evaluation criteria includes $\mathrm{R}^{2}$, adjusted $\mathrm{R}^{2}$ and Durbin Watson (DW). In next step, two tests are performed including Ramsey's reset stability test and Chow forecasts test.

\subsection{Co-Linearity of Independent Variables}

Independent variables against one another are shown in Figure 2 to predict the co-linearity probability.
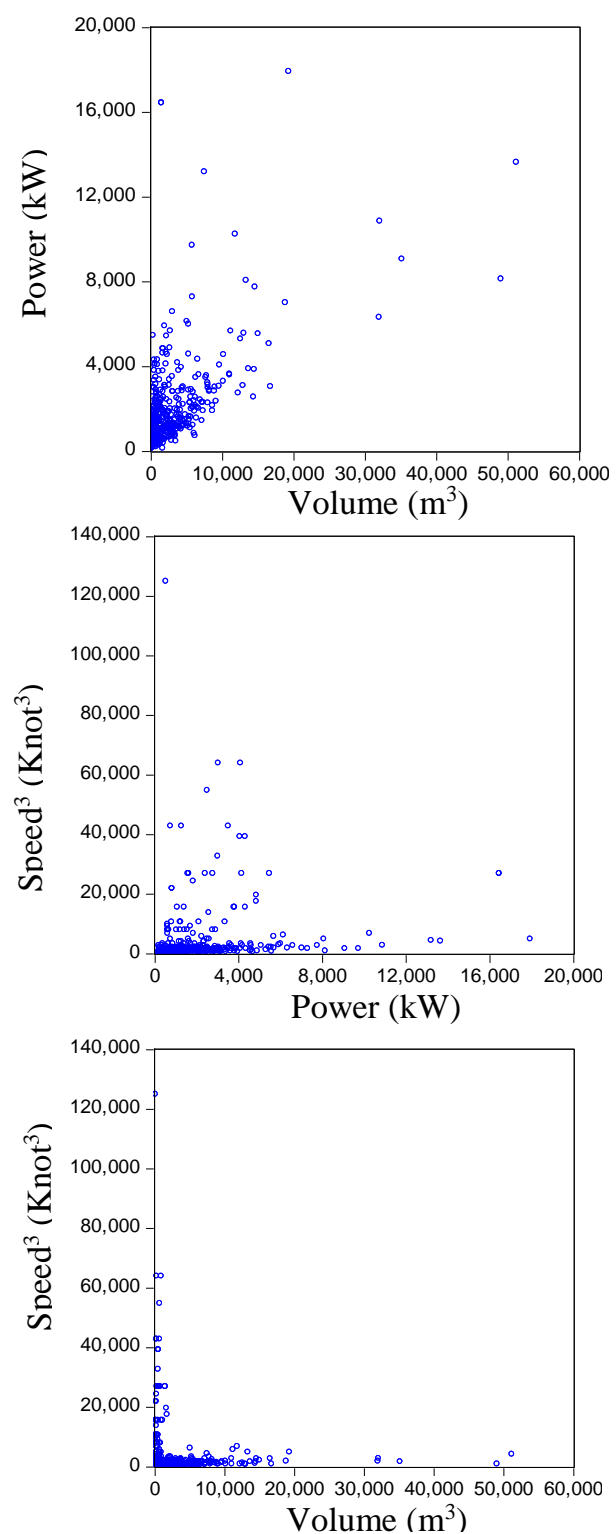

Figure 2. Analysis of variables variation against each other

The visual examination of the test results shows that there is no collinearity between these three variables.

\subsection{OLS Estimation}

By using three mentioned parameters, linear model is estimated using the ordinary least squares method according to $\mathrm{Eq}(4)$ on database including 452 marine vessels. Results are presented in Table 4 [23].

$F C=\beta_{1} P O W E R+\beta_{2}(S P E E D)^{3}+$

$\beta_{3}$ IMMERSED VOLUME $+U_{i}$ 
Table 4. OLS estimation of linear model

\begin{tabular}{lrlll}
\hline \multicolumn{1}{c}{ Variable } & Coefficient & \multicolumn{3}{c}{ Std. Error t-Statistic Prob. } \\
\hline \multicolumn{1}{c}{ POWER } & 0.111635 & 0.002937 & 38.00433 & 0.000 \\
SPEED33 & 0.004658 & 0.000581 & 8.021235 & 0.000 \\
\multicolumn{1}{c}{ VOLUME } & 0.005887 & 0.001355 & 4.344103 & 0.000 \\
\hline R-squared & 0.845117 & Mean dependent var & 253.88 \\
Adjusted R-squared & 0.844427 & S.D. dependent var & 295.08 \\
S.E. of regression & 116.3877 & Akaike info criterion & 12.358 \\
Sum squared resid & 6082199. & Schwarz criterion & 12.386 \\
Log likelihood & -2789.986 & Hannan-Quinn criter. & 12.369 \\
Durbin-Watson stat & 1.637503 & & \\
\hline
\end{tabular}

Coefficients of all variables are significant. As was mentioned, all independent variables are expected to have positive impact on increasing fuel consumption. So, the sign of all variables are acceptable [23].

Thus, the modified linear model of fuel consumption flow rate in liter per hour is defined in Eq.(5) by using three parameters of total power of main and auxiliary engines in kilowatt, economical speed in knot, and immersed volume in cubic meter.

$F C=0.1116354792 \times P O W E R+$

$0.0046580374 \times(S P E E D)^{3}+$

$0.0058874707 \times I M M E R S E D$ VOLUME $+U_{i}$

$\mathrm{R}^{2}$ and adjusted $\mathrm{R}^{2}$ are found to be about $84 \%$ which are very acceptable and show the fitness of the model. Durbin-Watson statistic for the autocorrelation detection of residual terms is equal to 1.64. This is near 2 and indicates the lack of autocorrelation [23]. Therefore, the evaluation criteria of the estimated model prove the validity and acceptability of the model. Now, the other tests can be done as described below.

\subsection{Stability Tests}

a) Ramsey RESET Test

As the results are shown in Table 5, probability is equal to 0.74 (greater than 0.05), so the null hypothesis of the accuracy of functional form is confirmed [23].

Table 5. Ramsey RESET test of linear model

\begin{tabular}{lccc}
\hline & Value & df & Probability \\
\cline { 2 - 4 } F-statistic & 0.303179 & $(2,447)$ & 0.7386 \\
Likelihood ratio & 0.612725 & 2 & 0.7361 \\
\hline
\end{tabular}

b) Chow Forecast Test

In this test, the model is estimated by 400 sections; then, it is applied on the last 52 sections. Test result (Table 6) shows that probability is equal to 0.73 (greater than 0.05) and represents structural stability and suitability of the model [23].

Table 6. Chow forecast test at section 400

\begin{tabular}{lccc}
\hline & Value & df & Probability \\
\cline { 2 - 4 } F-statistic & 0.869847 & $(53,396)$ & 0.7285 \\
Likelihood ratio & 49.77703 & 53 & 0.6004 \\
\hline
\end{tabular}

\section{Results of Modeling}

By eliminating time variable from Eq.(2) and using $\mathrm{S}=200$ and Density $=0.89$ for gasoil, approximate flow rate of fuel consumption is estimated by FAO equation as Eq.(6):

$$
\begin{aligned}
& F C=0.16854 \times \operatorname{MPOWER}(\mathrm{hp})= \\
& 0.22601 \times \operatorname{MPOWER}(\mathrm{kW})
\end{aligned}
$$

MPOWER in FAO equation is main engine power plus half of auxiliary engines power according to NIOPDC guidelines; whereas, the linear model (Eq.(5)) involves total main and auxiliary engines power.

Figure 3 displays the polynomial trend line (with order of five) of the fuel consumption calculated by the linear model (Eq.(5)), actual fuel consumption, and fuel consumption calculated by FAO formula (Eq.(6)) sorted in an ascending order for visual comparison of the modeling results. In general, the fuel consumption estimated by FAO formula is about $50 \%$ greater than that estimated by the linear model. So, the linear model gives a lower estimation of fuel consumption and fuel is allocated more purposefully in the whole database. It can be observed that the linear model is very close to actual value of fuel consumption.

Modeling results in Figure 3 shows that the linear model outperforms FAO formula. So, the linear model (Eq.(5)) can be chosen as the optimum formula for calculating the fuel consumption of marine vessels.

In Eq. (5), the regression coefficients $\beta_{1}, \beta_{2}$ and $\beta_{3}$ are known as partial regression or partial slope coefficients [15]. The meaning of partial regression coefficient is as follows:

$\beta_{1}=0.112$ measures the change in the mean value of fuel consumption per unit change in engines power, holding the value of speed and immersed volume constant. Put differently, it gives the "direct" or the "net" effect of a unit change in engines power on the mean value of fuel consumption, net of any effect that speed and immersed volume may have on mean value of fuel consumption [15].

Likewise, $\beta_{2}=0.005$ measures the change in the mean value of fuel consumption per unit change in speed with the power of three, holding the value of engine power and immersed volume constant.

Also, $\beta_{3}=0.006$ measures the change in the mean value of fuel consumption per unit change in immersed volume, holding the value of engine power and speed constant.

Also $U$, known as the disturbance or error term, is a random (stochastic) variable that has well-defined probabilistic properties. The disturbance term $U$ may well represent all those factors that affect fuel consumption but are not taken into account explicitly. 


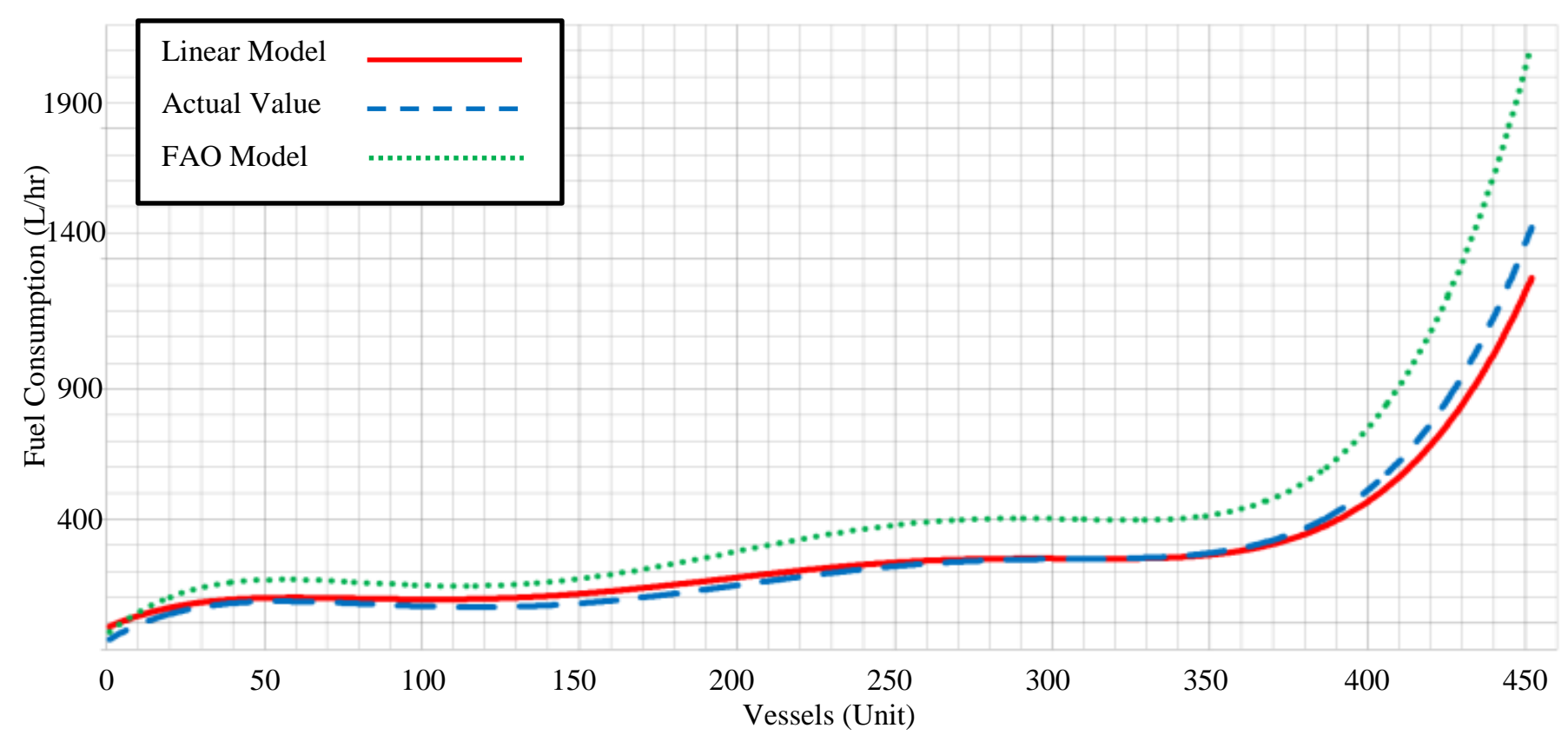

Figure 3. Comparison of actual and estimated fuel consumption

Since decimal digits have significant impact on the calculated value of fuel consumption, it is preferred to use Eq.(5). But, to display simple mathematical formula, it could be summarized as following:

$F C=0.112 \times P O W E R+0.005 \times$

$(S P E E D)^{3}+0.006 \times$

IMMERSED VOLUME $+U_{i}$

Therefore, the fuel consumption flow rate of the marine vessels in liter per hour is calculated by three parameters of total main and auxiliary engines power in kilowatt, economical speed in knot, and immersed volume in cubic meter. Immersed volume is calculated by multiplying three factors including length in meter, width in meter, and summer draft in meter. Also, to obtain the fuel consumption flow rate in cubic meter per hour, the calculated FC from Eq.(7) should be multiplied by $10^{-3}$.

Also, to obtain fuel consumption value for a voyage, Eq.(5) should be multiplied by sailing time. Sailing time in hour is achieved by dividing sailing distance by vessel speed. One knot is equal to 1.150782308 miles per hour (mph); so, sailing time is calculated by:

$$
\begin{aligned}
& \text { Sailing time }(\text { hour })= \\
& =\frac{\text { Distance }(\text { nautical mile })}{\text { Speed }(\text { knot })}= \\
& =\frac{\text { Distance }(\text { mile })}{1.150782308 \times \text { Speed }(\text { knot })}
\end{aligned}
$$

Therefore, voyage fuel consumption value in liter is calculated by:

Voyage $F C=F C \times$ Sailing time

or

\section{Conclusion}

So, approximate value of consumed fuel for sailing of marine vessels was obtained by econometric and regression analysis on 452 cross-sectional database. This linear model was created by three parameters, i.e. total main and auxiliary engine power, economical speed, and immersed volume. Stability tests including Ramsey RESET Test and Chow forecast test were done on the estimated model and the results confirm its validity. Therefore, the research result with good reliability could be used by NIOPDC for subsidized fuel allocation and by other shipping companies for estimating their ship fuel consumption. Results reveal that the amount of fuel consumption estimated by FAO formula is about $50 \%$ greater than the one estimated by the linear model for the whole database. So, the ration of fuel consumption is decreased by the linear model. This reduction of subsidized fuel allocation to marine vessels by $50 \%$ is purposefully. Official statistics show that about 2.5 million liters of subsidized fuel products are allocated to marine vessels every day. For example, when the price of subsidized gasoil and global price are considered to be 3000 IRR and 16000 IRR, respectively, this gap is defined as subsidy price. Then, $50 \%$ reduction in fuel ration will lead to saving of about 16.25 billion IRR for NIOPDC every day. This number amounts to about 487.5 billion IRR in one month and the huge amount of about 5,930 billion IRR in one year!

\section{Acknowledgment}

This paper was prepared by the helps and supports of the National Iranian Oil Products Distribution Company (NIOPDC).

$V F C=F C \times T$ 


\section{References}

1- M.J. Hutchinson, (1982), An Estimate of Operating Costs for Bulk, Ro-Ro and Container Ships, Australian Government Publications, Canberra, Australia.

2- A. Schrady, K. Smyth and B. Vassian, (1996), Predicting Ship Fuel Consumption, Tech. report, NPS-OR-96-007, Naval Postgraduate School, Monterey, California, May. See also URL http://www.nps.edu.

3- S. Davie, C. Minto, R. Officer, C. Lordan and E. Jackson, (2014), Modelling Fuel Consumption of Fishing Vessels for Predictive Use, ICES Journal of Marine Science, 72(2), June, pp. 708-719, doi:10.1093/icesjms/fsu084.

4- J.H.J. Hulskotte, B. Wester, A.M. Snijder, M. Rijnmond and V. Matthias, (2014), International Survey of Fuel Consumption of Seagoing Ships at Berth, Tech. report, CNSS Work package 5, Clean North Sea Shipping (CNSS), Rotterdam Main Port University of applied sciences, May. See also URL http://www.shipemissions.eu.

5- W. Górski, T.A. Gerigk and Z. Burciu, (2013), The Influence of Ship Operational Parameters on Fuel Consumption, Scientific Journals of the Maritime University of Szczecin, 36(8), May, pp. 49-54.

6- Q. Menga, Y. Dub and Y. Wanga, (2015), Shipping Log Data Based Container Ship Fuel Efficiency Modeling, Journal of Transportation Research, 83(16), May, pp. 207-229, doi: 10.1016/j.trb.2015.11.007.

7- B.P. Pedersen and J. Larsen, (2008), Modeling of Ship Propulsion Performance, World Maritime Technology Conference (WMTC2009), Jan.

8- T.E. Notteboom and B. Vernimmen, (2008), The Effect of High Fuel Costs on Liner Service Configuration in Container Shipping, Journal of Transport Geography, 17(5), May, pp. 325-337, doi: 10.1016/j.jtrangeo.2008.05.003.

9- J.H.J. Hulskotte and H.A.C. Denier van der Gon, (2009), Fuel Consumption and Associated Emissions from Seagoing Ships at Berth Derived from an OnBoard Survey, Journals of Atmospheric Environment, 44(10), May, pp. 1229-1236, doi: 10.1016/j.atmosenv.2009.10.018.

10- T. Borkowski, L. Kasyk and P. Kowalak, (2011), Assessment of Ships Engine Effective Power Fuel Consumption and Emission Using the Vessel Speed, Journal of KONES Powertrain and Transport, 18(2), May, pp. 31-39.

11- ACCESS, (2014), Calculation of Fuel Consumption per Mile for Various Ship Types and Ice Conditions in Past, Present and in Future, Tech. report, Project NO. 265863, Arctic Climate Change Economy and Society (ACCESS), May. See also URL http://www.access-eu.org.

12- P. Agnolucci, T. Smith and N. Rehmatulla, (2014), Energy Efficiency and Time Charter Rates: Energy Efficiency Savings Recovered by Ship Owners in the Panamax Market, Journal of Transportation Research, 66(14), May, pp. 173-184, doi: 10.1016/j.tra.2014.05.004.

13- N. Bialystocki and D. Konovessis, (2016), On the Estimation of Ship's Fuel Consumption and Speed Curve: A Statistical Approach, Journal of Ocean Engineering and Science, 1(16), May, pp. 157-166, doi: 10.1016/j.joes.2016.02.001.

14- EPA, (2000), Analysis of Commercial Marine Vessels Emissions and Fuel Consumption Data, Tech. report, Rep. EPA420-R-00-002, U.S. Environmental Protection Agency, Office of Transportation and Air Quality, May. See also URL https://www.epa.gov.

15- D.N. Gujarati, (2003), Basic Econometrics, 4th Edition, McGraw Hill Publications, New York, USA.

16- R. Heinrich, (1992), Cost Control in Forest Harvesting and Road Construction, Food and Agriculture Organization of the United Nations Publications, Rome, Italy.

17- NIOPDC Business Management Unit, (2015), Fuel Selling Instruction to Marine Vessels. (In Persian)

18- A.H. Safargholi, A. Mohammadi, M. Najjar, A. Hajmohammadi and S.M. Seyed Karimi, (2015), Iranian Marine Statistics, Vice-Presidency for Science and Technology of Presidency of the Islamic Republic of Iran. (In Persian)

19- F. Baldia, H. Johnsona, C. Gabrieliia and K. Anderssona, (2014), Energy Analysis of Ship Energy Systems - the Case of a Chemical Tanker, Journal of Energy Procedia, 61(14), May, pp. 1732-1735, doi: 10.1016/j.egypro.2014.12.200.

20- Tony Molland, (2008), Maritime Engineering Reference Book, Butterworth-Heinemann Publications, Burlington, USA.

21- D.A. Taylor, (1996), Introduction to Marine Engineering, Second Edition, Elsevier ButterworthHeinemann publications, Burlington, USA.

22- L. Jackson and T.D Morton, (1999), General Engineering Knowledge for Marine Engineers, Thomas Reed Publications, United Kingdom.

23- W.E. Griffiths, R.C. Hill and G.C. Lim, (2008), Using EViews for Principles of Econometrics, Third Edition, Wiley Publications, New Jersey, United States. 